\title{
Inline Blasting of Cast Parts
}

\author{
A new through-feed shot blast machine has been developed especially for forges and foundries. \\ It is highly automated, which ensures that tumble-proof parts can be processed efficiently on \\ large-scale production lines.
}

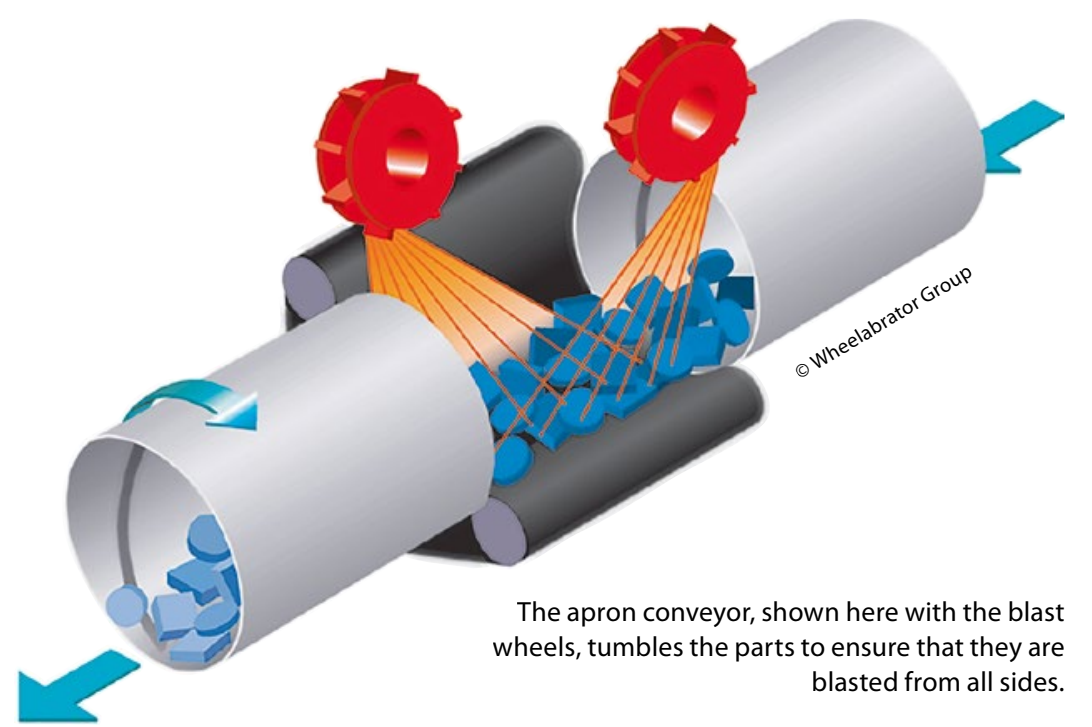

Wheelabrator has launched a new entrylevel model as part of its CT range of continuous through-feed blasting machines. The new machine (CT-2-45/7-430) is ideal for forges and foundries that need to shot blast castings inline and also require a high level of automation and excellent standards of quality.

This entry-level version has been developed by simplifying a proven design to produce a basic model that can be customised to meet individual requirements with a range of optional features. The drum has a smaller diameter and is single-walled, while the number of blast wheels is limited to two. This means that the machine is best suited to processing smaller parts or smaller quantities of larger parts (with a diagonal measurement of up to $700 \mathrm{~mm}$ ).

\section{Simplified maintenance}

The model is the first new machine to feature Wheelabrator's Comet HD blast wheel as standard. This range of machines is very versatile and offers new automation options, easy integration and highly reliable processes. During the development process, the key considerations were reliability, durability and ease of maintenance.

The CT range provides continuous, automated and flexible blast cleaning of tumble-proof parts, such as castings and forgings, and is ideally suited to integrated high-volume production and mixed product runs. For forges and foundries, this means efficient blasting with minimal space and storage requirements, short transport distances and little or no need for the manual handling of parts.

\section{Blasting from all sides}

The centrepiece of all CT machines is a continuous apron conveyor that reliably tumbles parts to ensure that they are blasted from all sides. The blast wheels are arranged to cover the entire length of the apron conveyor and point directly at the apron, where the parts are being tumbled.

The blast intensity is controlled by varying the throughput rate of the parts. This results in the best possible cleaning effect, together with minimal wear on the ma-

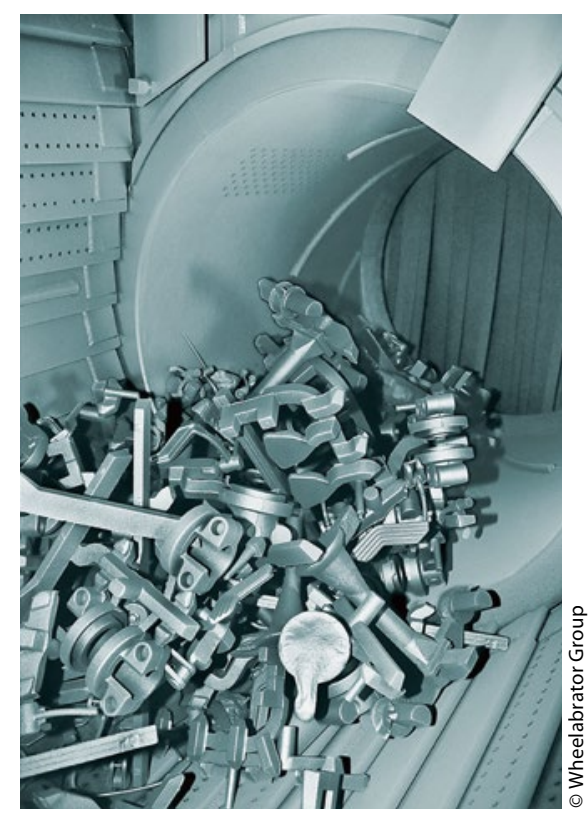

Castings passing through the blasting machine. The newly developed range of through-feed blasting systems offers a flexible, automated blasting process.

chine components and the abrasive. The barrel rotation speed and the abrasive throughput are electronically controlled on the basis of pre-programmed parameters.

In conjunction with its sister company Disa, Wheelabrator offers its CT machines as part of a complete, integrated foundry production line, with a continuous workpiece flow from liquid metal to cleaned part. //

\section{Contact}

Disa Industrie AG (Wheelabrator)

Bachenbülach, Switzerland

Tel. +41 448154000

zurich@wheelabratorgroup.com

www.wheelabratorgroup.com 